\title{
Professional Enrichment And Experiential Learning For Business Students
}

Elizabeth C. Ekmekjian, (E-mail: lisaek@optonline.net), William Paterson University Virginia A. Taylor, (E-mail: taylorv@wpunj.edu), William Paterson University

\begin{abstract}
College faculty members are faced with continuous challenges each day. The communication of knowledge and motivation and participation of students remains a goal of all. This paper discusses these issues and reports on the progress of one business college's efforts for continuous improvement. At the William Paterson University, Christos M. Cotsakos College of Business we recently implemented a new professional enrichment program designed to enhance a student's college education with active learning activities inside and outside the classroom. The active learning approach emphasizes the students' role in constructing knowledge by engaging in inquiry, critical thinking, and problem solving in a collaborative framework. Specific program examples are presented.
\end{abstract}

\section{Introduction}

t has never been easy to communicate knowledge. Faculty members have always had to find ways to organize course content and use presentation time effectively and efficiently in order to motivate students to get them to share our enthusiasm for our subject. Doing just this much is a regular
challenge for any faculty member, especially faculty responsible for large classes. However, even with excellent presentational style, student passivity remains a problem, especially in large impersonal lecture courses (Fredrick, 1987). The 1984 National Institute of Education report, Involvement in Learning: realizing the potential of American higher education, strategy recommends greater use of active teaching modes to increase student involvement. Over twenty-five years have passed since the Involvement report and it is safe to say that the majority of classrooms in most colleges are not awash with active learning opportunities. Active learning that involves students has also been found to be an effective intervention for classroom incivilities (Boice, 1996). Experiential learning for our students was accomplished through a number of workshops and activities, offering a wide diversity of skills an topical areas embodied within the professional enrichment initiative. We have incorporated numerous activities into a new professional enrichment program at William Paterson University (WPU). This paper will present an overview of the program and then define some specific examples with more detail.

\section{Overview Of The Professional Enrichment Program}

The Christos M. Cotsakos College of Business (CCOB) is seeking continuous improvement of its undergraduate and graduate programs as part of its efforts to become a premier business school. To this end we have adopted a professional enrichment initiative. Many funding and accrediting agencies have begun to examine and redefine the academic learning environment and focus on outcomes assessment. Therefore the educational environment has become learning-centered rather than teaching-centered. Universities adopting this approach are trying to show students how to learn, not just teach them the subject matter. Life-long learning skills will enhance their intellectual growth well beyond the semester's coursework.

Based on input from the University's valued stakeholders (students, alumni, faculty, community and business leaders), the college developed and implemented a new Professional Enrichment Program in the Fall semester of 2002. The program is designed to enhance a student's college education by providing opportunities to meet and network with area specialists, hear business leaders speak, become involved in work related activities such 
as internships, practicum, and job shadowing, and attend various seminars and forums that deal with professional development and/or contemporary work related issues.

Program Requirements: All students who become CCOB majors beginning with the Fall 2002 semester are required to complete the professional enrichment component of their educational experience prior to graduation. All students must earn professional enrichment points as they progress through their business program towards graduation. Accumulated points (earned during a student's enrollment at WPU) are utilized in partial fulfillment of the course requirements for one of the mandatory courses for all undergraduate business administration and accounting majors. A number of faculty also require per semester point requirements.

Students earn enrichment points through their involvement in Professional Enrichment activities (workshops, seminars, etc.); material participation in a CCOB sponsored Club; and attendance at a professional association meeting.

\section{Active Learning \& Professional Enrichment Activities}

Traditional age students are engaged in learning how to become adults and all of their activities, curricular and extra curricular, are influenced by this drive for personal growth. We have tried to address this young adult growth imperative and incorporate opportunities for such growth into our professional enrichment program. Students may need to learn how to do research, how to give a speech, or formulate a moral judgment. These PEP activities also provide useful peer interactions and an opportunity to work in a team setting.

Two sessions of the Business Etiquette Workshop were offered where students learned the do's and don'ts of business etiquette at the lunch/dinner table and in general. Our expert took us step-by-step through a business meal including: walking through the door, shaking hands, seating yourself, ordering food, proper use of utensils, and ending the meal on the right foot. Each was quite successful. Student request and feedback was very positive and the sessions will be offered on a continuous basis.

Information Technologies and Library Services: Lifelong Learning Skills Workshop was offered by the Assistant Director and business liaison of the David and Lorraine Cheng Library at William Paterson University. She advised students of the wealth of information available to them including technological resources and related materials which are invaluable in assisting business leaders in project development and analysis. She will show students how to use the University's E*TRADE Financial Learning Center data bases which provide a running stream of financial information on listed companies as well as how to access the wealth of historical data in Compustat.

Case Analysis Workshop: This situational analysis workshop uses a decision as the pivot for discussion and participation in the formation of a thought matrix to form a more holistic picture, rather than only focusing on one criteria such as the bottom line. The goal is to generate more solutions and a list of priorities. To experience problems phenomenologically, students must identify and dwell on what makes them problematic (Brookfield, 1987.) Accordingly we asked students to identify and explore alternative ways of thinking, to question both assumptions and analysis criteria and to use analytics and analytical results to confirm the decision makes sense. Applications of this analysis process help our student decision-makers to both illustrate knowledge of the subject domain and clearly articulate reasons for the essay answer/recommended action/final decision/personal vote. The thought matrix model encourages thoughtful consideration and prioritized support for multiple goals. In the core message of what really drives the success of student learning or case analysis, critical thinking skills are near the top of the list. These mental habits can be applied across disciplines. The underlying goal of this workshop was to teach them how to create what Kurfiss (1988) calls "dialogic exchange" between their views and those who think differently. In order to accomplish this, several critical thinking tasks to actively engage students with open-ended questions that do not have one right answer were designed. 


\section{Concluding Thoughts And Future Directions}

In conclusion, active learning is an attitude and excellent teaching tools are available. Bean (2001) is an excellent reference tool. As college courses, accreditation requirements, and government agencies shift the primary focus to student learning outcomes, the teacher's role and college's role is changing from "the-sage-on-the-stage to the guide-by the-side" (Stimson and Miller, 1996, 40). Our professional enrichment program has drawn active learning ideas and support from professors in every discipline across the Christos M. Cotsakos College of Business. Some workshops were originally part of a particular class and they have now been opened to all our students.

At WPU an annual Stakeholders' Conference is used to guide continuous improvement. Attendees at the conference included a number of CCOB faculty along with approximately twelve representatives from each of the following groups of Stakeholders: undergraduate students, undergraduate alumni, graduate students, graduate alumni, business leaders, and the academic community. The Fall 2002 stakeholder event addressed technology applications as well as reading, writing and speaking across the curriculum. Outcome assessment of the 2002 conference provided insights and recommendations to incorporate more technology across the curriculum and activities to improve students' listening, decision, presentation and writing skills. Accordingly the future activities of the Professional Enrichment Program incorporate these ideas with new initiatives for 2003.

For example, based on these recommendations, the CCOB incorporated technology skills standardized examinations in its Information System courses (required by all business and accounting majors). These exams will be used to test a student's computer knowledge of Word, Excel, Power Point, Access and HTML and the web. If a student fails a portion of the exam, he/she will be required to attend a Professional Enrichment workshop in that area. A follow-up exam will be given to determine whether or not the student has obtained these basic skills.

To address additional recommendations, new Professional Enrichment activities will be offered including: computer skills classes in Word, Excel, Power Point, Access and HTML and the web; business ethics seminar; mock interview workshop; and a stress management workshop. The new WPU Russ Berrie Institute Interactive Sales Lab is scheduled to be up and running late Fall 2003. State of the art conference rooms featuring robotic video cameras and plasma display screens in each practice room will facilitate analysis of the presentation process with instant replay digital video feedback.

As you can see, the CCOB has incorporated active learning through its Professional Enrichment Program and will continue to do so in its efforts for continuous improvement.

\section{References}

1. Bean, J. 2001. Engaging Ideas: The Professor's Guide to Integrating Writing, Critical Thinking, and Active Learning in the Classroom. San Francisco: Jossey-Bass

2. Brookfield, S.D. 1987. Developing Critical Thinkers: Challenging Adults to Explore Alternative Ways of Thinking and Acting. San Francisco: Jossey-Bass.

3. Kurfiss, J.G. 1988. Critical Thinking: Theory Practice, and Possibilities. ASHE-ERIC Higher Education Report No. 2 Washington, D.C.: ERIC Clearinghouse on Higher Education and the Association for the Study of Higher Education

4. National Institute of Education. 1984. Involvement in learning: realizing the potential of American higher education. Washington D. C.: U.S. Department of Education.

5. Stimson, J.E. and R.G. Miller. 1996 Problem-based learning in business education: Curriculum design and implementation issues" in Bringing problem-based learning.33-42. 
Notes 